\title{
Analgesia en artroplastía de cadera: bloqueo de plexo lumbar versus fascia iliaca suprainguinal
}

\author{
Bravo D.1, Layera S.1, Jara Á. ${ }^{1}$, Fernández D. ${ }^{1}$, Barrientos C. ${ }^{2}$, Wulf R. ${ }^{2}$, Aliste J. ${ }^{1}$ \\ 1 Departamento de Anestesiología y Medicina Perioperatoria, Universidad de Chile, Santiago, Chile. \\ 2 Departamento de Traumatología y Ortopedia, Universidad de Chile, Santiago, Chile.
}

Introducción: El plexo lumbar entrega inervación importante de la cadera y sus tejidos circundantes, constituyendo el blanco actual para la analgesia después de una artroplastía total de cadera (ATC). El bloqueo del plexo lumbar (BPL) es una opción lógica, sin embargo, se han reportado serias complicaciones que llevan a la búsqueda de una alternativa que sea igualmente efectiva pero más segura. Por su parte, el bloqueo de la fascia iliaca suprainguinal (BFIS) pudiese tener un perfil de riesgo menor ya que se realiza en un plano superficial, subfascial y lejos de estructuras vitales. En este estudio pretendemos comparar el desempeño analgésico de ambos bloqueos tras la realización de una ATC.

Metodología: Se realizó un estudio prospectivo, randomizado y ciego, planteando como outcome primario el consumo de morfina a las 24 horas. La técnica quirúrgica, anestésica y analgésica se estandarizó. En el postoperatorio inmediato, los participantes fueron aleatorizados 1:1 a recibir un BPL o BFIS guiados por ultrasonido empleando 40 $\mathrm{ml}$ de levobupivacaína al $0,25 \%$ con epinefrina $5 \mathrm{ug} / \mathrm{ml}$. Se registraron además datos técnicos, consumo de morfina a las 48 horas, tiempo al primer rescate analgésico, dolor en reposo y dinámico a las 3-6-12-24-48 horas, efectos secundarios del uso de opioides, complicaciones del bloqueo, limitación fisioterapéutica (por dolor o bloqueo motor) y días de estadía hospitalaria.

Resultados: Se reclutaron 30 pacientes en total, evidenciándose sólo un bloqueo fallido (BPL). El consumo de morfina $(\mathrm{mg})$ fue de 7,21 $(7,13)$ versus 6,26 (6,82) a las 24 horas $(\mathrm{p}>0,05)$, y 4,42 $(7,92)$ versus 1,6 $(2,02)$ a las 48 horas $(\mathrm{p}>0,05)$ para BPL y BFIS, respectivamente. El tiempo al primer rescate analgésico fue de 427,25 $(382,4)$ minutos para BPL y de 285,8 $(171,8)$ minutos para BFIS ( $p>0,05)$. El dolor en reposo y dinámico a las 3, 6, 12, 24 y 48 horas no demostró diferencias significativas entre ambos abordajes, ni tampoco hubo diferencias en la capacidad de realizar fisioterapia, efectos secundarios de opioides o estadía hospitalaria. Sólo el tiempo de ejecución fue discretamente más breve en favor de BPL; 3,7 (1,9) versus 5,1 $(1,8)$ minutos $(\mathrm{p}=0,05)$. No hubo complicaciones asociadas a los procedimientos.

Conclusiones: Preliminarmente, el BFIS constituye una alternativa analgésica efectiva tras una ATC, logrando un desempeño similar al del BPL tanto en consumo de morfina como en control del dolor. Por sus características técnicas, resulta esperable un perfil riesgo/beneficio más favorable. Se requieren más estudios que complementen estos resultados.

https://doi.org/10.25237/congresoclasa2019.04 